Article

\title{
Can Facebook Aid Sustainability? An Investigation of Empathy Expression within the Humans of New York Blog
}

\author{
Hannah Wheeler and Courtney Quinn * \\ Earth and Environmental Sciences, Sustainability Science, Furman University, 3300 Poinsett Hwy, \\ Greenville, SC 29613, USA; hannah.wheeler@furman.edu \\ * Correspondence: courtney.quinn@furman.edu
}

Received: 28 March 2017; Accepted: 8 June 2017; Published: 10 June 2017

\begin{abstract}
This qualitative study offers a novel exploration of the links between social media, virtual intergroup contact, and empathy by examining how empathy is expressed through interactions on a popular social media blog. Global leaders are encouraging individuals to engage in behaviors and support policies that provide basic social foundations. It is difficult to motivate people to undertake such actions. However, research shows that empathy intensifies motivation to help others. It can cause individuals to see the world from the perspective of stigmatized group members and increase positive feelings. Social media offers a new pathway for virtual intergroup contact, providing opportunities to increase conversation about disadvantaged others and empathy. We examined expressions of empathy within a popular blog, Humans of New York (HONY), and engaged in purposeful case selection by focusing on (1) events where specific prosocial action was taken corresponding to interactions on the HONY blog and (2) presentation of people in countries other than the United States. Nine overarching themes; (1) perspective taking, (2) fantasy, (3) empathic concern, (4) personal distress, (5) relatability, (6) prosocial action, (7) community appreciation, (8) anti-empathy, and (9) rejection of anti-empathy, exemplify how the HONY community expresses and shares empathic thoughts and feelings.
\end{abstract}

Keywords: empathy; intergroup contact theory; social media; pro-environmental behavior; social foundations; sustainability; Facebook; Humans of New York

\section{Introduction}

"HONY, you transport me into the lives, minds and hearts of beautiful souls I have the privilege of sharing this planet with. Others I probably would not have met on my own journey."

- HONY follower

Following fifteen years of worldwide effort to meet the Millennium Development goals, in 2015 the United Nations ratified the 2030 Sustainable Development Goals, recognizing the triple dimensions of sustainability; people, prosperity, and the planet. Vowing to eradicate poverty while protecting Earth's natural resources, 193 countries will seek to achieve 17 goals in the next fifteen years, ranging from improved sanitation to gender equality to combating climate change [1,2]. Yet, humans continue to put undue pressure on Earth's resources, and if harmful actions are prolonged, both biophysical and human systems will be irrevocably disrupted $[3,4]$. The ultimate challenge of the UN Sustainability Goals will be to avoid environmental thresholds while simultaneously providing critical social foundations to over 11 billion people by 2030 .

To reach these ambitious goals, world leaders are encouraging all people to engage in behaviors and support policies that protect the environment and provide basic social foundations, especially to 
those in developing countries most affected by poverty, war, and environmental crisis [5-7]. One key question is: How are people motivated to support such policies and undertake such actions? Research on empathy offers a pathway to examine whether increasing empathetic concern for others distant to us in space (or time) can aid in increasing support for, and behaviors to, protect the environment and support humanity. Previous research has shown that compassion and empathy guide moral actions, and other-oriented tendencies are an important factor for pro-environmental behavior [8]. However, can we expect people to have empathy for others when people have never experienced the places or met the people most vulnerable environmental change? To ask people to care about, and take action regarding, the fate of others fails to acknowledge that it is difficult to empathize with people one cannot relate to or interact with [9].

Yet, with international connectivity increasing via social media, a new avenue for interaction and increasing empathy has emerged [10]. Studying the consequences of the ubiquitous nature of social media is a newly emerging field of research where we are just beginning to understand how virtual interaction with others impacts our own thoughts and behaviors [11].

\subsection{Empathy}

Empathy can be defined as the reactions of one individual to the observed experiences of another $[12,13]$. Scholars have determined that sympathy, tenderness, compassion, altruism, etc., are not synonymous with empathy, but constitute specific dimensions of the concept. For example, compassion explicitly addresses feelings for the suffering of others [8] and altruism is behavior intended to benefit another, sometimes requiring sacrifice from the actor [14,15].

Empathy can cause us to see the world from the perspective of a stigmatized group and make us feel more positively towards individuals [13] as well as toward the whole group [16]. There are also visible consequences of empathy, such as increased action on behalf of a disadvantaged group such as donations and service [17]. Study participants who show a high empathy level display stronger pro-social [18] and pro-environmental behaviors and attitudes [19-22]. Therefore, one way to increase support for programs and policies benefitting social foundations could be by inducing empathy and increasing identification with people living in other places and future generations [23].

\subsection{The Contact Hypothesis}

In studying prejudice, Allport [24] proposed that contact between people of different groups serves to reduce bias and prejudice by increasing empathy as one interacts with and learns more about a different category of people. Empirical research has since demonstrated that intergroup contact reduces prejudice among the majority group [25] towards many other-groups including; black neighbors [16], gay men [26], disabled people [27], and has been shown to reduce prejudice in conflict situations [28].

\subsection{Imagined Contact Hypothesis}

In some cases, it may be impossible for individuals to have opportunities for face-to-face contact with other-groups. Therefore, an important question regarding intergroup contact is; is face-to-face contact needed to reduce prejudice? Crisp and Turner [29] proposed that contact between individuals need not be direct to elicit benefits. Merely imagining positive interaction with a member of an out-group can elicit the same results as physical interactions [30]. Studies with various outgroups have shown the positive effects of imagined contact including; the elderly [31], gay men [26], Muslims [32-35], illegal immigrants [36] and people with schizophrenia [37].

\subsection{Parasocial Contact}

Merely watching a character from an other-group on screen can elicit feelings of sympathy and reduce prejudice. Indirect media-mediated intergroup interactions through storybooks [38], and T.V. shows [39-41] can lead to a decrease in prejudice just as real-world face-to-face interactions. 


\subsection{Parasocial Intergroup Contact in the Age of the Internet}

Alarmingly, longitudinal research is showing that empathy is decreasing [42,43]. Scholars are concerned about the role technology (specifically access to smartphones and social media) is playing in reducing empathetic concern in children and college students [44]. However, as the internet becomes more ubiquitous to our everyday lives, it becomes increasingly important to investigate whether and how social media can provide opportunities to increase (or at least provide an outlet for) empathy and reduce prejudice. These new parasocial interactions can be used as tools to promote positive multi-cultural and intergroup relations [45-49] through frequent computer-mediated communication [50] The virtual contact via social media provides a potential for new online intergroup contact strategies that may be key to developing empathy in today's highly connected globalized world [51].

Yet, few studies have examined the role of Facebook in improving in-group/out-group prejudice or acceptance of others. Schwab and Greitemeyer [48] proposed that even being passively exposed to other cultures on Facebook could improve general attitudes towards diverse cultural groups. By examining Facebook 'friends' of users, they were able to show a positive relationship between having out-group members as 'friends' and a positive and general out-group attitude. Schumann et al. [52] examined Facebook interactions beyond users' immediate circle of 'friends' by examining discourse in Facebook groups based upon nationality, religion, or gender. They found that, over time, comments expressing mutual acceptance increased and prejudice decreased. Prosocial media use is linked to increased levels of long-term prosocial behavior and empathy [53].

In this study, we examine virtual interactions on a social media blog not dedicated to linking people with similar viewpoints or lifestyles and does not specifically seek to connect people through imagined or parasocial intergroup connections. The blog we chose to examine for expressions of empathy is a storytelling blog of normal people in a large U.S. city.

\section{Methods}

\subsection{Humans of New York Blog}

Brandon Stanton began the Humans of New York (HONY) blog in the summer of 2010. Stanton's initial goal was to photograph 10,000 New Yorkers, and create a catalog of the city's residents. Stanton began to collect quotes and short stories from photograph subjects he met on the street and added a short narrative to each photo. Stanton does not offer specific advocacy or opinions about his subjects, merely their own words. What resulted was a photography blog fused with captions that gained worldwide attention. Currently, HONY has over 20 million followers, and has inspired three books by Stanton which feature photos and stories posted from the blog. We began with the hypothesis that HONY provides a platform for virtual parasocial intergroup contact and is therefore a valuable study mechanism for expressions of virtual empathy, especially given its immense global reach.

\subsection{Procedure}

The process used in this study can best be described as a collective case study [54,55]. In our purposeful case selection, we focused on two specific time frames, (1) a series of posts that included a middle school aged African-American boy named Vidal from a high poverty area of New York and his school and (2) a series that captured Stanton's world tour conducted on behalf of the United Nations in 2014. All posts and comments related to Vidal $(n=50)$ and the UN tour $(n=182)$ were initially collected. Most original posts have a minimum of 500 comments from blog followers associated with them, though many have more than 20,000. Therefore, we used purposeful sampling [54] to identify posts from each of the two time frames. For the Vidal case study, we chose interactions between Stanton, Vidal, and the principal of Vidal's school, Mrs. Lopez. In addition, we chose posts that captured the main storyline along with results, which included pictures with Vidal's family and their eventual meeting with President Barack Obama. For the U.N. tour, we chose 15 photos spanning 12 countries. 
Next, the full text of each (1) original post, (2) comments from blog followers, and (3) responses/discussion about comments by blog followers, were fully categorized to identify the portions of the post's dataset pertinent to this research. We began our collective case study analysis guided by the work of Davis $[12,56]$ to create an a priori coding scale based on the Interpersonal Reactivity Index (IRI) used to measure individual's empathy. The four subscales in the IRI include perspective taking (PT), fantasy scale (FS), empathic concern (EC), and personal distress (PD) (Table 1). The subscales provide a multidimensional approach to empathy and previous research has shown that these scales are important aspects of empathy because they reflect the variety of reactions to others that can be referred to as empathy [12].

Coding was done in successive rounds working post by post, with discussion of content and emerging themes between each original post. Distinct iterations of coding were conducted to increase reliability by allowing themes to be revised as needed [57,58]. As themes emerged that were distinct from the original a priori codes, they were added to the coding protocol and posts recoded to include all themes. This resulted in the creation of a subset of the original data that specifically focused on the four a priori codes and five emergent themes, termed (1) relatability, (2) pro-social action, (3) community appreciation, (4) anti-empathy, and (5) rejection of anti-empathy (Table 1).

Table 1. Nine unique codes were developed during content analysis. The table provides the definitions and examples for each code.

\begin{tabular}{|c|c|c|}
\hline Code & Definition & Example from Data \\
\hline Perspective Taking (PT) & Ability to see from another's point of view & $\begin{array}{l}\text { "This is why it's troubling to hear people speak of } \\
\text { inequality as though the impoverished are to blame. } \\
\text { Can you imagine trying to get out of that situation } \\
\text { when stuff like this is happening around you?" }\end{array}$ \\
\hline Fantasy Scale (FS) & $\begin{array}{l}\text { Ability to imagine feelings and actions of } \\
\text { fictitious characters }\end{array}$ & $\begin{array}{l}\text { "I'm imaging the laughter, high fives and joy these kids } \\
\text { must be experiencing right now. I hope they know that } \\
\text { they matter and they know that they are loved." }\end{array}$ \\
\hline Empathic Concern (EC) & $\begin{array}{l}\text { Sympathetic feelings or concern for } \\
\text { disadvantaged others }\end{array}$ & $\begin{array}{l}\text { "My "like" of this is a hug to this man from many miles } \\
\text { away." }\end{array}$ \\
\hline Personal Distress (PD) & Self-oriented feelings of personal anxiety & $\begin{array}{l}\text { "It actually pains me physically when I consider that } \\
\text { it's people that throw around balls for a living that } \\
\text { make millions of dollars and not people like this } \\
\text { woman." }\end{array}$ \\
\hline Relatability (RT) & $\begin{array}{l}\text { Showing or making a connection between } \\
\text { personal experiences and another's } \\
\text { experiences. }\end{array}$ & $\begin{array}{l}\text { "I'm a single mother trying to get my Ph.D. I hope my } \\
\text { 7-year-old daughter sees me the same way you see } \\
\text { your mother." }\end{array}$ \\
\hline Prosocial Action (PSA) & $\begin{array}{l}\text { Statements intended to benefit another. } \\
\text { Code also includes calls to action. }\end{array}$ & "I'm in the mood to eradicate poverty." \\
\hline Community Appreciation (CA) & $\begin{array}{l}\text { Recognizing and celebrating the efforts of } \\
\text { community infrastructure and community } \\
\text { members on the HONY blog. }\end{array}$ & $\begin{array}{l}\text { "Wow this is absolutely awesome! I am so amazed by } \\
\text { the wonderful work that Humans of New York is doing } \\
\text { with his influence." }\end{array}$ \\
\hline Anti-Empathy (AE) & $\begin{array}{l}\text { The opposite of one or a combination of the } \\
\text { following: PT, FS, EC, PD, RT, PSA, and CA. }\end{array}$ & $\begin{array}{l}\text { "He's a deceiver. And lies to cover himself. He helps no } \\
\text { one." }\end{array}$ \\
\hline Rejection of Anti-Empathy (RAE) & $\begin{array}{l}\text { Intolerance for other community members } \\
\text { expressing anti-empathy }\end{array}$ & "... You have to be the most ignorant person on earth." \\
\hline
\end{tabular}

\section{Results and Discussion}

\subsection{Perspective Taking}

People commented that before following the HONY blog, they were unable to take the perspective of another because they were unaware of the lives of others around the globe. These people were formally so disengaged with global issues that they failed to recognize the everyday lives, and specifically the plights, of others. "I've been on this earth for almost 30 years and I feel like this page has shown me a whole other side of things that's going on in other countries that I just knew nothing about." People report awakening to the world which then allowed them to feel for others. "I can honestly say a few weeks ago I didn't care what was going on within other countries and I didn't empathize with the people of the Middle East". 
Another aspect of being unaware was acknowledgement of previously held biases based upon missing or skewed information regarding the lives of lay-people in other countries. "I've viewed the entire Middle East, especially Arab nations, as violent, hateful, inhumane, oppressive, and dangerous. I didn't know children play outside and people go to college. I didn't realize little girls wear dresses there. Nothing I learned at any educational institution taught me those things. I've always perceived the Middle East as bad and crazy. I've seen these photos and thought, "'there are actual people there.'" In particular, comments show that the HONY blog allowed people to see the 'humanness' of others living peaceful, everyday lives, that are from regions where most media reporting shows chaos and violence. "These posts show you the real Middle East. Kids playing in the street, loving families, hard workers and a generous welcoming culture. But also the real struggles they face. Unemployment, poverty, war crimes. But the difference is you humanize their struggle. Thank you for showing the world Arabs are not just numbers." The experience of reading the HONY blog allowed people to transition from an attitude of dismissal or disengagement to the knowledge of others from other countries and cultures.

The most common way people considered the perspective of others was by considering the commonalities of all people. "Everyone is struggling. There is someone out there afraid of the same thing I am, worried about the same thing I am worried about, sorry for something they did, ashamed, trying really hard, overcoming fears, dealing with self-confidence issues, and overthinking everything. We are all the same." One way people acknowledged our "sameness" was by referring to the humanizing effect of reading the blog. "I am using these photos to humanize the Middle East." Commenters not only referred to the blog's ability to humanize people, but acknowledging their ability to feel better connected to others. For example: "Every day, HONY allows me to better connect with humanity and feel a greater sense of compassion." On the other hand, some commenters discussed the differences between human beings. "Humans have different opinions, that's what makes us interesting. If your opinions are the only right ones maybe you need to do some thinking about who is hating who." A facet to this PT includes a special theme that emerged during coding; ascertaining that as individuals, we should not assume that we know the life story of another. There were many examples of this theme: "And this is why I can never assume I know what anyone is going through." Also, "I thought I knew what it was like to struggle... Then I read this. I have no idea."

Recognizing the differences in people's lifestyles and hardships also led commenters to take a new perspective on their own life. Although this aspect of PT does not directly put one in the place of another, it changes how people view their more fortunate circumstances. "Your pictures always move me, but since you started photographing Iraq, I can't shake the image and the story from my head all day long. It doesn't even seem right to walk in my air conditioned kitchen and gaze at my food choices or worry if my child has the right pair of tennis shoes." HONY posts often allow people to see their own privilege in comparison to others. "I used to and still cry and crib about things like not getting the best marks, the best university and everything. But reading all these HONY posts really puts things into perspective. This is going on in places while I am sleeping at home and worrying about inconsequential things." The most explicit examples of PT were illustrated in the use of phrases such as "what a feeling ... " and "I wonder what she feels." One commenter stated, "I've never come close to being in his shoes, but I can almost feel what he felt. Your posts are so raw and honest and I appreciate how you can make us feel, without having been there." Some considered the perspective of a photo subject when they commented, "And think, from the daughter's perspective, what it would mean to choose a husband that her family didn't approve of." Commenters even engaged in PT regarding President Obama. "Must've been so relieving for him to get a chance to speak about personal troubles. Everywhere else, he's supposed to play the role of a public figure".

\subsection{Fantasy Scale}

Through coding, we found that the fantasy scale was not entirely relevant to our study. This was because items on the fantasy scale are meant to measure an individual's tendency to identify with characters in fictional situations, such as books and films [56]. The purpose of the HONY blog is to present real people for others to connect with. Although the photo subjects were often far removed 
from the blog commenters, and occasionally commenters were imagining how others felt, "I'm imaging the laughter, high fives and joy these kids must be experiencing right now. I hope they know that they matter and they know that they are loved," it would be incorrect to identify them as fictional, or characters for that matter.

\subsection{Empathic Concern}

Commenters who displayed EC commonly showed sympathetic feelings or concern for disadvantaged others. A primary method of showing concern was seen through an expression of protectiveness. Some individuals on the blog were driven to defend photo subjects they felt were being taken advantage of. One woman commented, "My momma bear instincts are coming out and I' $m$ not even a mom! Just want to scoop him up and protect him".

Additionally, pity was shown for photo subjects. "What I feel for this man is beyond sadness..." Many commenters promised prayers and positive thoughts, or even Stanton. "I will keep your efforts in prayer and look forward to more posts about this." Many instances of EC manifested in phrases such as, "I wish I could do more than donate, or share your stories and educate those around me, I wish there was more," or "I wish she had enough in life that she could have the luxury of a few simple dreams." Commenters longed for the ability to help and comfort photo subjects.

Many individuals realized how fortunate they were by comparing their own lives to those of the photo subjects. One photo showed a broken hearted man who was unable to marry the woman he loved due to his own social standing. A commenter remarked, "Take a second to appreciate the privilege of being able to love someone of your own choosing." Others stated that they were thankful they did not have to worry about some of the problems that the photo subjects had, and that they felt sympathetic toward them.

Many expressions of EC utilized the words suffer and struggle. Primarily, these words were used to acknowledge that others were going through difficult times, and the commenters were able to empathize with that. For example, "God bless all those people that are suffering," and "It breaks my heart that people have to live this way and struggle day to day..."

One of the most interesting comments was from a parent using the HONY blog to teach empathy to her children. The parent utilized the blog picture to provide an opportunity for her children to learn about their own social and economic privilege in comparison to children from another country who have little. "Just shared and explained the picture to my kids. Awakening for them. The worst thing in the world is not ...not getting a game from GameStop or an American girl doll. We empathize with these kids ....my kids were on the verge of tears. This is the real world. Not Disney channel or nick jr. Maybe they will choose to help change the world when they grow up. Make the most of their freedoms and opportunities in the us. Thank you Brandon! Be safe!"

\subsection{Personal Distress}

Instances of PD were characterized by emotional reactions and physical responses. Emotional reactions included declarations such as, "this is so heartbreaking" and "probably one of the saddest things I have ever read." Commenters were sometimes angry and frustrated, "This makes me ANGRY!" and "I'm enraged ..." The final emotional expression of PD was concern or worry, exemplified by comments such as, "I was worry about these kids".

Physical responses included people feeling sick after reading the stories or looking at photos: "[This] makes me sick... " People reported feeling pain as a type of empathic response. For example, one commenter said, "It actually pains me physically when ... " Finally, a common response was people saying they were so sad or distraught after looking at the blog that they were crying. Examples include, "You're making me cry," or, "I have welled eyes and chills". 


\subsection{Relatability}

A recurring topic within Relatability was family. People relate their family members to the people in blog photos, helping commenters feel a personal connection to the outgroup. "I also have a disabled son in a wheelchair," "I have family in both Syria and Iraq," and "As a single mom of a little boy ... " Other commenters empathized with photo subjects because they came from similar environments. In Vidal posts, people commented, "So glad to see HONY in my hometown," and "I came from a neighborhood just like these kids." The UN post comments indicated empathy from people who had either visited the other countries or were born there.

Commenters were able to relate by noticing the similar roles they had to people from the HONY posts. For example, "I have learning disabilities and I still remember my first day in my first AP class," was commented to relate to the students from the Vidal case study who needed encouragement in school. Many commenters talked about occupations that were similar to those of the photo subjects; "I teach at a minority school in South Georgia."

A final prevalent theme was the statement, "I am." This occurred at the beginning of many different comments, including those about family, similar environments, and similar roles. "I am a product of Brownsville," "I am a Syrian guy who just moved to the USA looking for good education," "I AM in his 'shoes' and have walked the journey for decades".

\subsection{Prosocial Action}

Instances of prosocial action can be separated into two general categories: call to prosocial action and manifestation of prosocial action. Commenters who fell into the former asked for others to volunteer in their local communities or wondered how they could start a fundraiser. Common questions were similar to the following: "Is it possible to start a kickstarter or fundraiser to help this fellow human?" and "Does anyone have an address I can ship to these children and their fellow refugees?" Others asked for help for their own communities, and called others to take prosocial action toward them; "PLEASE HELP US!! THE WORLD IS IGNORING US!!! \#DemandForAction."

Alternatively, people took prosocial action that can be quantified. Specifically donating to a fundraiser, or offering different services are on a separate level from asking what can be done, or telling others to do something. For example, a commenter wrote, "The World Literacy Foundation would like to get involved in any way!" and went on to give contact information. Another commenter said, "I work for JetBlue and we get $2 R T$ tickets for every $25 \mathrm{~h}$ of community service that we perform. I gave $150 \mathrm{~h}$ of service and as a result I have quite a few positive space airline tickets that I would like to donate." During the Vidal photo series, a fundraising website was set up for Mott Hall Bridges Academy, and \$1,418,334 was raised by 51,466 people in 20 days [59].

Overall, there was a consistent theme of "we." People constantly referred to "We as a society," or "If we all [did something]..." Whether people were suggesting prosocial action or participating in it, the general consensus was, "We need to work together as a global community. Not against each other".

\subsection{Community Appreciation}

Community members often expressed appreciation for how HONY allows them to learn about others, express empathy, and connect with people around the world. Most commonly, commenters expressed CA by simply saying "Thank you." Sometimes, the thank you was directed toward the blog as a whole, a specific commenter, or Brandon Stanton. Others thanked photo subjects. Commenters were thankful for (1) an unbiased representation; "I applaud you for your unbiased depiction in the photographs and descriptions," (2) compassion and love from people involved in the blog; "[HONY] has restored my faith in the inherent goodness of people and made me realize that one person with good intentions can change the world," (3) inspiring content; "Such inspiring stories and positive vibes! I love HONY," (4) the blogs ability to humanize its subjects; "Every day, HONY allows me to better connect with humanity and feel a greater 
sense of compassion," and (5) the hope for a better future; "I love this entire community and it honestly gives me hope for the human race".

\subsection{Anti-Empathy and Subsequent Rejection of Anti-Empathy}

We felt it was important to document instances of Anti-Empathy to show where the blog was not inducing the same empathic feelings to every commenter. AE expressions were seen toward the photo subject, other commenters, groups outside of the picture, and to the blog (or Brandon Stanton). An example of AE toward a photo subject is manifested in the comment, "How bout, get a job and take care of your granny," which was directed toward someone who was unemployed and relied on their grandmother. During the Vidal series, a commenter displayed AE to another commenter when he said, "You are very very naive if you think Obama and the democratic party had nothing to gain PR-wise by meeting with Vidal." One commenter felt a post was triggering for people with suicidal tendencies, and said, "You post to millions of people, have some accountability." Other times, groups who were not involved in the post initially were shown AE. For example, speaking about Obama, one commenter wrote, "He's a damn Muslim...I have no respect for him or his wife. We need them out of our White House." Islam was not involved in the original post. We also noted that expletives were commonly used in AE expressions.

Sometimes, RAE may seem to parallel AE because commenters who refute those displaying AE may not seem to be taking on the perspective of the commenters. However, we felt that it was important to distinguish RAE because these commenters were able to identify others' lack of empathy and compassion. For example, "ur lack of compassion and understanding is astounding," "The lack of empathy is inhumane and truly disgusting," and "It's sad that people can't simply feel compassion for this child." The RAE comments were specifically referring to the AE of other commenters, not photo subjects or Stanton. These posts also frequently used expletives.

\subsection{Study Limitations}

Within this study, we could not ascertain whether or not following HONY increases empathy for outgroups. Perhaps those following HONY already display high levels of outgroup empathy and HONY is merely a vehicle to express such concerns. We could only work with available comments, any comments deleted by the original commenter or Stanton were not available for the study, perhaps limiting negative comments or views. Attitudes and opinions shared on Facebook may be more a result of social norms and conscious posturing than actual empathy. In addition, the positive outcome of money donated to the Mott Hall Bridges Academy could be due to social norms and bandwagon effects rather than empathy.

Arguably, the sample of comments taken from the blog may not have been written by a diverse group of commenters. HONY might attract Facebook users with inclinations to express empathy or anti-empathy. Therefore, the IRI categories validated by the comments and the further categories developed from the IRI may be reflected in this sample, but would not be validated on another platform providing virtual intergroup contact.

\subsection{Future Research}

In this study, we showed expressions of empathy, but were not able to show whether the HONY blog creates or increases empathy. Future empirical research, currently being conducted by the authors, will measure pre and post levels of empathy from engagement with the HONY blog. Data on the demographics of commenters is unavailable, so we were unable to test the theory that people are more likely to show empathy to those more similar towards them. As big data sets become more available, the demographics of HONY blog community members may provide interesting insights. Some previous studies have attempted to measure increased empathy, and have done so by taking demographics into account. Davis $[12,56]$ used the IRI to develop a questionnaire with subscales to measure self-reported empathic reactions to scenarios. Future research may attempt to adapt this questionnaire in order to poll blog contributors. This type of questionnaire would allow for deeper 
understanding of the type of people who express empathy, how they express it, to what degree empathy is expressed, and what scenarios, images, etc. induce the expressions.

At least one pro-social behavior, monetary donations towards Mott Hall Bridges Academy, has directly resulted from the HONY blog. Yet, it is impossible to know whether people donated out of a sense of empathy or another reason, perhaps a social norm or to feel a part of the community. In addition, there is no way to know whether people who reported empathetic feelings subsequently took additional actions motivated by empathy: contacting an elected official, volunteering for the less fortunate etc. Future research should examine whether or not virtual intergroup contact and increased empathy inspire people to take actions that will lead to a more sustainable world. We need to explore how reduced prejudice and intergroup contact can increase support for the social, political, and economic changes needed to support aggregate victims or outgroups, as well as how computer mediated communication can facilitate such support.

\section{Conclusions}

The HONY blog provides a distinct opportunity to examine empathetic expression and virtual intergroup contact as the HONY community is a rare social media-based vehicle for connecting with strangers on an unprecedented worldwide scale. We found ample support for the a priori codes associated with the IRI Empathy Scale as well as additional expressions of empathy throughout comments and discussions. With over 15 million followers, the HONY platform provides a trove of information on how people are interacting with others from out-groups over the internet.

We have demonstrated a link between virtual intergroup contact, virtual empathy, and acknowledgement of attitudes and even specific behaviors (monetary donations) on the HONY blog. Our HONY case study of Vidal also provides support for research showing that people are willing to help an outgroup member that has been individualized, or personalized [60]. Some encouraging studies [17] show that empathy for a member of a stigmatized group will motivate action for members of the group. However, even more challenging will be achieving social foundations (food, water, energy, jobs, gender equality, political representation) for all of humanity. Reaching these goals will require more than helping individualized victims of poverty, inequality, and violence. Achieving social foundations will require support for larger social changes such as national and international policies, changes in economic systems, and changes in lifestyles of ingroup members that indirectly negatively affect outgroup members. This initial study provides exciting support for the HONY blog as a research subject for reducing prejudice, allowing for empathetic responses, increasing empathy, and promoting prosocial and pro-environmental behaviors.

Acknowledgments: The authors would like to acknowledge support by the Furman University Libraries Open Access Fund and a Furman Advantage Scholarship.

Author Contributions: Hannah Wheeler and Courtney Quinn conceived and designed the research methods; Hannah Wheeler performed the research; Hannah Wheeler and Courtney Quinn analyzed the data; Hannah Wheeler and Courtney Quinn wrote the paper.

Conflicts of Interest: The authors declare no conflict of interest.

\section{References}

1. The Millennium Development Goals Report 2015. Available online: http://www.un.org/millenniumgoals/ 2015_MDG_Report/pdf/MDG\%202015\%20rev\%20\%28July\%201\%29.pdf (accessed on 10 September 2015).

2. UN Adopts New Global Goals, Charting Sustainable Development for People and Planet by 2030. Available online: https://www.un.org/development/desa/en/news/sustainable/un-adopts-new-global-goals.html (accessed on 25 September 2015).

3. Rockström, J.; Steffen, W.; Noone, K.; Persson, Å.; Chapin, F.S.; Lambin, E.F.; Lenton, T.M.; Scheffer, M.; Folke, C.; Schellnhuber, H.J.; et al. A safe operating space for humanity. Nature 2009, 461, 472-475. [CrossRef] [PubMed] 
4. $\quad$ Raworth, K. A Safe and Just Space for Humanity: Can We Live within the Doughnut? Oxfam Discussion Paper; Oxfam: Oxford, UK, 2012; pp. 1-26.

5. Showstack, R. Obama calls for more action on climate change during State of the Union address. EOS 2013, 94, 78-79. [CrossRef]

6. Ones, D.S.; Dilchert, S. Environmental sustainability at work: A call to action. Ind. Organ. Psychol. 2012, 5, 444-466. [CrossRef]

7. Bendell, J.; Little, R. Seeking sustainability leadership. J. Corp. Citizensh. 2015, 60, 13-26. [CrossRef]

8. Pfattheicher, S.; Sassenrath, C.; Schindler, S. Feelings for the suffering of others and the environment: Compassion fosters proenvironmental tendencies. Environ. Behav. 2016, 48, 929-945. [CrossRef]

9. Batson, C.D.; Turk, C.L.; Shaw, L.L.; Klein, T.R. Information function of empathic emotion: Learning that we value the other's welfare. J. Pers. Soc. Psychol. 1995, 68, 300-313. [CrossRef]

10. Prot, S.; Anderson, C.A. Research Methods, Design, and Statistics in Media Psychology. In The Oxford Handbook of Media Psychology; Dill, K., Ed.; Oxford University Press: New York, NY, USA, 2013; pp. 109-136.

11. Alvídrez, S.; Piñeiro-Naval, V.; Marcos-Ramos, M.; Rojas-Solís, J.L. Intergroup contact in computer-mediated communication: The interplay of a stereotype-disconfirming behavior and a lasting group identity on reducing prejudiced perceptions. Comput. Hum. Behav. 2015, 52, 533-540. [CrossRef]

12. Davis, M.H. Measuring individual differences in empathy: Evidence for a multidimensional approach. J. Pers. Soc. Psychol. 1983, 44, 113-126. [CrossRef]

13. Batson, C.D.; Polycarpou, M.P.; Harmon-Jones, E.; Imhoff, H.J.; Mitchener, E.C.; Bednar, L.L.; Klein, T.R.; Highberger, L. Empathy and attitudes: Can feeling for a member of a stigmatized group improve feelings toward the group? J. Pers. Soc. Psychol. 1997, 72, 105-118. [CrossRef] [PubMed]

14. Monroe, K.R. A fat lady in a corset: Altruism and social theory. Am. J. Polit. Sci. 1994, 38, 861-893. [CrossRef]

15. Kollmuss, A.; Agyeman, J. Mind the gap: Why do people act environmentally and what are the barriers to pro-environmental behavior? Environ. Educ. Res. 2002, 8, 239-260. [CrossRef]

16. Pettigrew, T.F. Intergroup contact theory. Annu. Rev. Psychol. 1998, 49, 65-85. [CrossRef] [PubMed]

17. Batson, C.D.; Chang, J.; Orr, R.; Rowland, J. Empathy, attitudes, and action: Can feeling for a member of a stigmatized group motivate one to help the group? Pers. Soc. Psychol. B. 2002, 28, 1656-1666. [CrossRef]

18. Decety, J. The neuroevolution of empathy. Ann. N. Y. Acad. Sci. 2011, 1231, 35-45. [CrossRef] [PubMed]

19. Berenguer, J. The effect of empathy in proenvironmental attitudes and behaviors. Environ. Behav. 2007, 39, 269-283. [CrossRef]

20. Markowitz, E.M.; Goldberg, L.R.; Ashton, M.C.; Lee, K. Profiling the "pro-environmental individual": A personality perspective. J. Pers. 2012, 80, 81-111. [CrossRef] [PubMed]

21. Pahl, S.; Bauer, J. Overcoming the distance: Perspective taking with future humans improves environmental engagement. Environ. Behav. 2013, 45, 155-169. [CrossRef]

22. Schultz, P.W. Empathizing with nature: Toward a social-cognitive theory of environmental concern. J. Soc. Issues 2000, 56, 391-406. [CrossRef]

23. Ericson, T.; Kjønstad, B.G.; Barstad, A. Mindfulness and sustainability. Ecol. Econ. 2014, 104, 73-79. [CrossRef]

24. Allport, G.W. The Nature of Prejudice, 3rd ed.; Addison-Wesley: Cambridge, MA, USA, 1979.

25. Pettigrew, T.F.; Tropp, L.R. A meta-analytic test of intergroup contact theory. J. Pers. Soc. Psychol. 2006, 90, 751-783. [CrossRef] [PubMed]

26. Turner, R.N.; Crisp, R.J.; Lambert, E. Imagining intergroup contact can improve intergroup attitudes. Group Process. Intergroup Relat. 2007, 10, 427-441. [CrossRef]

27. Pettigrew, T.F.; Tropp, L.R.; Wagner, U.; Christ, O. Recent advances in intergroup contact theory. Int. J. Intercult. Rel. 2011, 35, 271-280. [CrossRef]

28. Hewstone, M.; Brown, R. Contact is not enough: An intergroup perspective on the "contact hypothesis". In Contact and Conflict in Intergroup Encounters; Hewstone, M., Brown, R., Eds.; Basil Blackwell: Cambridge, MA, USA, 1986; pp. 1-44.

29. Crisp, R.J.; Turner, R.N. Can imagined interactions produce positive perceptions? Reducing prejudice through simulated social contact. Am. Psychol. 2009, 64, 231-240. [PubMed]

30. Crisp, R.J.; Turner, R.N. The Imagined Contact Hypothesis. In Advances in Experimental Social Psychology; Olson, J., Zanna, M.P., Eds.; Academic Press: Orlando, FL, USA, 2012; Volume 46, pp. 125-182. 
31. Abrams, D.; Crisp, R.J.; Marques, S.; Fagg, E.; Bedford, L.; Provias, D. Threat inoculation: Experienced and imagined intergenerational contact prevents stereotype threat effects on older people's math performance. Psychol. Aging 2008, 23, 934. [CrossRef] [PubMed]

32. Husnu, S.; Crisp, R.J. Elaboration enhances the imagined contact effect. J. Exp. Soc. Psychol. 2010, 46, $943-950$. [CrossRef]

33. Husnu, S.; Crisp, R.J. Imagined intergroup contact: A new technique for encouraging greater inter-ethnic contact in Cyprus. Peace Confl. 2010, 16, 97-108. [CrossRef]

34. Turner, R.N.; Crisp, R.J. Imagining intergroup contact reduces implicit prejudice. Br. J. Soc. Psychol. 2010, 49, 129-142. [CrossRef] [PubMed]

35. Turner, R.N.; West, K. Behavioural consequences of imagining intergroup contact with stigmatized outgroups. Group Process. Intergroup Relat. 2012, 15, 193-202. [CrossRef]

36. Harwood, J.; Paolini, S.; Joyce, N.; Rubin, M.; Arroyo, A. Secondary transfer effects from imagined contact: Group similarity affects the generalization gradient. Br. J. Soc. Psychol. 2011, 50, 180-189. [CrossRef] [PubMed]

37. West, K.; Holmes, E.; Hewstone, M. Enhancing imagined contact to reduce prejudice against people with schizophrenia. Group Process. Intergroup Relat. 2011, 14, 407-428. [CrossRef] [PubMed]

38. Cameron, L.; Rutland, A.; Brown, R. Promoting children's positive intergroup attitudes towards stigmatized groups: Extended contact and multiple classification skills training. Int. J. Behav. Dev. 2007, 31, 454-466. [CrossRef]

39. Castelli, L.; De Dea, C.; Nesdale, D. Learning social attitudes: Children's sensitivity to the nonverbal behaviors of adult models during interracial interactions. Pers. Soc. Psychol. B 2008, 34, 1504-1513. [CrossRef] [PubMed]

40. Schiappa, E.; Gregg, P.B.; Hewes, D.E. Can one TV show make a difference? A Will \& Grace and the parasocial contact hypothesis. J. Homosex. 2006, 51, 15-37. [PubMed]

41. Schiappa, E.; Gregg, P.B.; Hewes, D.E. The parasocial contact hypothesis. Commun. Monogr. 2005, 72, 92-115. [CrossRef]

42. Konrath, S.H.; O'Brien, E.H.; Hsing, C. Changes in dispositional empathy in American college students over time: A meta-analysis. Pers. Soc. Psychol. Rev. 2011, 15, 180-198. [CrossRef] [PubMed]

43. Twenge, J.M.; Campbell, W.K.; Freeman, E.C. Generational differences in young adults' life goals, concern for others, and civic orientation, 1966-2009. J. Pers. Soc. Psychol. 2012, 102, 1045-1062. [CrossRef] [PubMed]

44. Turkle, S. Reclaiming Conversation: The Power of Talk in a Digital Age; Penguin Press: New York, NY, USA, 2015.

45. Amichai-Hamburger, Y.; Furnham, A. The positive net. Comput. Hum. Behav. 2007, 23, 1033-1045. [CrossRef]

46. Hoter, E.; Shonfeld, M.; Ganayim, A. Information and communication technology (ICT) in the service of multiculturalism. Int. Rev. Res. Open Distrib. Learn. 2009, 10, 1-15. [CrossRef]

47. Walther, J.B. Computer-mediated communication and virtual groups: Applications to interethnic conflict. J. Appl. Commun. Res. 2009, 37, 225-238. [CrossRef]

48. Schwab, A.K.; Greitemeyer, T. Failing to Establish Evaluative Conditioning Effects for Indirect Intergroup Contact on Facebook. Basic Appl. Soc. Psychol. 2015, 37, 87-104. [CrossRef]

49. Wilhelm, A.G. Democracy in the Digital Age: Challenges to Political Life in Cyberspace; Routledge: New York, NY, USA, 2000.

50. Caplan, S.E.; Turner, J.S. Bringing theory to research on computer-mediated comforting communication. Comput. Hum. Behav. 2007, 23, 985-998. [CrossRef]

51. White, F.A.; Harvey, L.J.; Abu-Rayya, H.M. Improving intergroup relations in the Internet age: A critical review. Rev. Gen. Psychol. 2015, 19, 129-139. [CrossRef]

52. Schumann, S.; van der Linden, N.; Klein, O. Bridging the gap on Facebook: Assessing intergroup contact and its effects for intergroup relations. Cyberpsychol. Behav. Soc. Netw. 2012, 15, 411-416. [CrossRef] [PubMed]

53. Prot, S.; Gentile, D.A.; Anderson, C.A.; Suzuki, K.; Swing, E.; Lim, K.M.; Horiuchi, Y.; Jelic, M.; Krahé, B.; Liuqing, W.; et al. Long-term relations among prosocial-media use, empathy, and prosocial behavior. Psychol. Sci. 2014, 25, 358-368. [CrossRef] [PubMed]

54. Creswell, J.W. Qualitative Inquiry and Research Design: Choosing Among Five Approaches, 3rd ed.; SAGE: Thousand Oaks, CA, USA, 2012.

55. Yin, R. How to Do Better Case Studies. In The SAGE Handbook of Applied Social Research Methods, 2nd ed.; Bickman, L., Rog, D.J., Eds.; SAGE: Thousand Oaks, CA, USA, 2009; pp. 254-282. 
56. Davis, M.H. A multidimensional approach to individual differences in empathy. Cat. Sel. Doc. Psychol. 1980, 10, 85-104.

57. Hruschka, D.J.; Schwartz, D.; St. John, D.C.; Picone-Decaro, E.; Jenkins, R.A.; Carey, J.W. Reliability in coding open-ended data: Lessons learned from HIV behavioral research. Field Methods 2004, 16, 307-331.

58. Stemler, S. An overview of content analysis. PARE 2001, 7, 137-146.

59. Let's Send Kids to Harvard: Vidal Scholarship Fund. Generosity. Available online: https://www. generosity.com/community-fundraising/let-s-send-kids-to-harvard-vidal-scholarship-fund (accessed on 12 January 2016).

60. Small, D.A.; Loewenstein, G. Helping a victim or helping the victim: Altruism and identifiability. J. Risk Uncertain. 2003, 26, 5-16. [CrossRef]

(C) 2017 by the authors. Licensee MDPI, Basel, Switzerland. This article is an open access article distributed under the terms and conditions of the Creative Commons Attribution (CC BY) license (http:/ / creativecommons.org/licenses/by/4.0/). 